\title{
Values and sense of symbolic immortality among non-religious adolescents in Poland
}

\author{
Michat faśkiewicz \\ Institute of Psychology, University of Gdansk, Gdansk, Poland
}

BACKGROUND

The aim of the study was to determine the values (Schwartz's ten basic values) and sense of symbolic immortality among non-religious adolescents.

PARTICIPANTS AND PROCEDURE

Participants were recruited from secondary schools in Gdansk and Gdynia.

\section{RESULTS}

The results showed that non-religious adolescents achieved higher results in the natural mode, and lower in biological-creative and religious modes. They also scored higher on universalism and self-direction subscales of Schwartz's ten basic values. The results are discussed in the light of humanistic personal ideology and terror management theory.

\section{CONCLUSIONS}

The cultural worldview that protects non-religious adolescents against death anxiety seems to be more rooted in humanistic and individualistic values.

\section{KEY WORDS}

adolescents; symbolic immortality; values

CORRESPONDING AUTHOR - Michał Jaśkiewicz, Institute of Psychology, University of Gdansk, 4 Bażyńskiego Str., 80-952 Gdansk, Poland, e-mail: psymj@ug.edu.pl

AUthors' CONTRIBution - A: Study design - B: Data collection · C: Statistical analysis · D: Data interpretation .

E: Manuscript preparation · F: Literature search · G: Funds collection

TO CITE THIS ARTICLE - Jaśkiewicz, M. (2014). Values and sense of symbolic immortality among non-religious adolescents in Poland. Current Issues in Personality Psychology, 2(3), 171-176. 


\section{BACKGROUND}

The sense of symbolic immortality was introduced to psychology by the American psychiatrist Robert Jay Lifton (1974) based on observations of people who survived the nuclear attack on Hiroshima. He noted that no matter how "lifeless" they seemed, as a result of experienced trauma, they expressed the desire to connect their own lives with something that exceeds the duration of the physical self. The need for symbolic immortality is universal, but may be expressed in different ways, depending on the culture and individual differences. According to Lifton (1979), the sense of symbolic immortality can be attained by five modes of experiencing: (1) biological - the sense that one is the continuation of past generations and that one will continue to live in one's progeny; (2) creative - the sense that one's work, and one's personal influence, will live on so that one's creative contribution to culture and society will not cease after death; (3) natural - feeling of being a part of a universe that is beyond oneself; (4) religious - the possibility of transcending death through spiritual and religious attainment); and (5) experiential - the capacity to lose oneself in other elements of the human flow.

The question of how non-religious people cope with the knowledge of the inevitability of death becomes important in the face of cultural and societal changes that are observed in Western culture: privatization of religion, emphasizing the role of individual thinking and action, and development of consumer society. In addition to the strong influence of the Roman Catholic Church in Poland and declared religiosity, after 1989 there could also be observed an increase in the importance of individual freedom, erosion of social capital and the growing importance of materialism. Thus, it seems important to investigate the specificity of cultural values that are declared by non-religious people. So far, those questions have been formulated mainly in terror management theory (for review: Solomon, Greenberg, \& Pyszczynski, 2000).

The sense of symbolic immortality moderates the effect of mortality salience on judgments of moral transgressions (Florian \& Mikulincer, 1998). As a result of mortality salience, people with a higher sense of symbolic immortality were less inclined to punish the moral transgressor. Thus, they do not defend their worldview in the way predicted by terror management theory. The sense of symbolic immortality works as a psychological resource that enables one to cope with the awareness of the inevitability of death. A similar conclusion may be drawn from the work of Dechesne et al. (2003), in which encouraging participants to believe in an afterlife (literal immortality) resulted in them not be- ing engaged in the defense of values. If literal and symbolic immortality are substitutable, it could be expected that non-religious people (in domains other than the religious one) will demonstrate a higher sense of symbolic immortality, because the belief in the immortality of the soul (literal immortality) is one of the strongest beliefs shared by Catholics in Poland (CBOS, 2009).

The values tested in this study are based on the circular model of Schwartz (1992), who distinguished ten core values: Universalism (social justice, equality, protection of the environment); Benevolence (helpfulness, honesty, forgiving); Tradition (humble, devout, accepting my portion in life); Conformity (politeness, obedience, honoring parents and elders); Security (national security, social order, clean); Power (social power, authority, wealth); Achievement (successful, capable, ambitious); Hedonism (pleasure, enjoying life); Stimulation (daring, varied life, exciting life); Self-direction (creativity, curious, freedom). These values are located in two dimensions: Self transcendence - Self enhancement and Openness to change - Conservation.

The circular model of values has also been confirmed in a Polish sample (Cieciuch, 2013). Research on Polish adolescents (Cieciuch, 2013) showed that preference for security, self-direction and achievement increase, whereas preference for stimulation and hedonism decrease with age of respondents.

As Cieciuch (2013) noted, in Schwartz's theory terminal values are considered as the real values that reflect beliefs or conceptions about ultimate goals of existence. Therefore, it can be assumed that attempts to imbue the meaning of one's existence to transcend the physical finitude described by the construct of symbolic immortality should be linked to the preference for specified, trans-situational and motivating goals. For example, it can be expected that a person with a stronger sense of symbolic immortality in the experiential domain should also be more strongly motivated by values reflecting the search for sensations, pleasure or sensual experience (e.g. stimulation and hedonism). In addition, Schwartz's theory of basic value and the construct of symbolic immortality share the assumption of an active role of the individual as a meaning seeker. If humans are inexhaustible meaning makers (Heine, Proulx, \& Vohs, 2006), it should be demonstrated both in values and in a sense of symbolic immortality.

In addition, research shows that religious people tend to favor values that promote conservation of social and individual order - power, security, conformity - and, conversely, to dislike values that promote openness to change and autonomy such as stimulation and self-direction (Saroglou, Delpierre, \& Dernelle, 2004). However, it is not clear wheth- 
er a reverse or similar pattern should be expected among non-religious adolescents in Poland.

\section{CURRENT STUDY}

On the basis of prior research and theoretical notions concerning religiosity, values and symbolic immortality, I assumed that values and sense of symbolic immortality may differ according to religiosity of young adults. I assume the following hypotheses: (1) non-religious adolescents will score lower on religious mode of symbolic immortality; (2) non-religious adolescents will score higher on natural and experiential modes of symbolic immortality; (3) nonreligious adolescent will score lower on Conservation values and will score higher on Openness to Change values. The study design consisted of a correlational study in which participants were asked to fill in questionnaires.

\section{PARTICIPANTS AND PROCEDURE}

\section{PARTICIPANTS}

One hundred and fourteen pupils (68 women, $M=16.90$ ) participated in the study. Participants were recruited from secondary schools in Gdansk and Gdynia. Non-religious adolescents were recruited during ethics lessons (the alternative to Roman Catholic religion lessons in Polish schools). From the sample of ethics lessons' students, some participants declared belonging to the Seventh Day Adventist Church or to Jehovah's Witnesses and were removed from the final sample. Fifty-seven ethics lesson students declared being agnostic or atheist. The control group consisted of 57 participants who declared being Roman Catholics.

\section{MEASURES}

The participants completed the following questionnaires:

1. Polish version of Portrait Value Questionnaire (Schwartz et al., 2001). This questionnaire is composed of 40 items that were designed to measure ten values (self-direction, stimulation, hedonism, achievement, power, security, conformity, tradition, benevolence, universalism). The participants indicated to what degree this person was similar to them, using a scale from: (1) not at all similar to me, to (6) very similar to me.

2. Polish translation of the Sense of Symbolic Immortality Scale (Matthews \& Kling, 1988). The scale has not been adapted in Poland. This scale is designed to measure five modes of symbolic immortality: religious, natural, creative, biological, and experiential. The scale consists of 30 items. Participants used a 7-point Likert response format.

\section{RESULTS}

\section{SENSE OF SYMBOLIC IMMORTALITY}

In the current study, a factor analysis with Varimax rotation yielded four main factors that explained $57 \%$ of the variance. The first factor explained $24 \%$ of the variance and included the six items that tap the biological mode and the six items that tap the creative mode. That is, at least in the Polish sample, the biological and creative modes were combined into a single factor. Similar results with one biological-creative factor were obtained by Florian and Mikulincer (1998) in an Israeli sample. The second factor explained 13\% of the variance and included the six items that tap the natural mode. The third factor explained $12 \%$ of the variance and included the six items that tap the religious mode. Finally, the fourth factor explained $7 \%$ of the variance and included the six items that tap the experiential mode.

Analysis of reliability of the subscales also shows satisfactory results, with Cronbach's $\alpha .87$ for the biological-creative mode, .91 for the natural mode, .82 for the religious mode, and .70 for the experiential mode.

Analysis of variance (ANOVA) revealed that non-religious adolescents scored significantly higher in the natural mode of symbolic immortality and significantly lower in biological-creative and religious modes - see Table 1 .

\section{VALUES}

One-way ANOVAs were conducted on each of ten values. The analysis showed that compared to the control group, non-religious adolescents scored higher on universalism, self-direction, and stimulation (on a trend level). As might be expected, they also scored lower on tradition - see Table 1 .

\section{CORRELATIONAL MATRIX}

Analysis of correlation between sense of symbolic immortality and values was conducted for each group separately - see Table 2 . Among the non-religious group, the natural mode of symbolic immortality was linked to openness to change values (self-direction, stimulation) and achievement, whereas the biological-creative mode was linked to conservation values and benevolence. No significant correlates were found for the religious mode. 
Table 1

Means of ten basic values and modes of symbolic immortality among non-religious adolescents and control group

\begin{tabular}{|c|c|c|c|c|}
\hline & Non-religious & Control & $F$ & $p$ \\
\hline \multicolumn{5}{|l|}{ Value } \\
\hline Self-direction & 5.07 & 4.75 & 7.15 & .009 \\
\hline Stimulation & 4.65 & 4.29 & 3.72 & .056 \\
\hline Hedonism & 4.78 & 4.57 & 1.32 & n.s. \\
\hline Achievement & 4.31 & 4.28 & 0.01 & n.s. \\
\hline Power & 3.22 & 3.12 & 0.24 & n.s. \\
\hline Security & 3.23 & 3.34 & 0.41 & n.s. \\
\hline Conformity & 3.18 & 3.23 & 0.59 & n.s. \\
\hline Tradition & 2.47 & 2.90 & 9.29 & .003 \\
\hline Benevolence & 4.56 & 4.43 & 0.84 & n.s. \\
\hline Universalism & 4.42 & 4.06 & 4.63 & .030 \\
\hline \multicolumn{5}{|l|}{ Symbolic immortality } \\
\hline Biological-Creative & 55.57 & 60.38 & 4.40 & .038 \\
\hline Natural & 34.33 & 32.42 & 4.00 & .040 \\
\hline Religious & 12.17 & 19.49 & 23.76 & $<.001$ \\
\hline Experiential & 24.24 & 23.35 & 0.32 & n.s. \\
\hline
\end{tabular}

Among the control group of adolescents, similar to the non-religious group, the natural mode was associated with openness to change values, as well as to achievement, power, benevolence and universalism. The biological-creative mode was, as in the non-religious group, linked to conservation values and benevolence, but additionally to stimulation, achievement and universalism. Contrary to the non-religious group, the religious mode of symbolic immortality was significantly linked to conservation values (tradition, conformity, security) as well as to self-transcendence values (benevolence and universalism).

\section{DISCUSSION}

According to Florian and Mikulincer (1998), biological and creative modes of symbolic immortality are probably the most relevant way by which people in Western, secular societies attain a sense of continuity and transcendence (Lifton, 1979). In the light of the presented results, it seems that young non-religious Poles to the highest extent invest in the natural mode of symbolic immortality.

This kind of strategy can be specific and effective for adolescents, because in most ways, individual achievements and biological offspring are not yet available resources to deal with the knowledge of the inevitability of death.
The analysis also proved that while the control group adolescents' modes of symbolic immortality are mostly associated with conservative values and self-transcendence, for the group of non-religious adolescents these associations did not appear. Although most studies usually indicate the severity of conservative attitudes as a result of confrontation with existential anxieties (Landau et al., 2004; Landau, Greenberg, Solomon, Pyszczynski, \& Martens, 2006), the natural mode, in which non-religious participants scored higher, was more closely linked to openness to change values. Conservative values reflect the preferences of order, a stable world and resistance to change. It allows one to imbue reality with meaning and structure in the face of awareness of the inevitability of death.

However, the non-religious adolescents demonstrate a mechanism similar to that described by Greenberg, Simon and Pyszczynski (1992), where participants in the mortality salience condition were more prone to adhere to important subjective values such as liberalism and tolerance. Probably the cultural worldview of non-religious adolescents that buffers them against death anxiety is more rooted in humanistic and individualistic values. Adherence to values such as universalism, self-direction and stimulation seems to reflect the humanistic personal ideology (de St. Aubin, 1996).

The results are also consistent with the analysis proposed by Koole and van den Berg (2004). Human- 
Table 2

Correlations between Sense of symbolic immortality and Structure of value among non-religious group of adolescents and control group

\begin{tabular}{|c|c|c|c|c|}
\hline \multirow[t]{2}{*}{ Non-religious adolescents } & \multicolumn{4}{|c|}{ Sense of symbolic immortality } \\
\hline & $\begin{array}{c}\text { Biological- } \\
\text { Creative }\end{array}$ & Natural & Religious & Experiential \\
\hline Self-direction & .01 & $.42^{* *}$ & -.06 & .18 \\
\hline Stimulation & .03 & $.27^{*}$ & .03 & -.01 \\
\hline Hedonism & .06 & $.46^{* *}$ & .13 & .17 \\
\hline Achievement & .08 & $.33^{*}$ & -.06 & .16 \\
\hline Power & .14 & .21 & -.00 & -.12 \\
\hline Security & .30 & .05 & .13 & .11 \\
\hline Conformity & $.38^{* *}$ & -.12 & .00 & -.04 \\
\hline Tradition & $.31^{*}$ & -.02 & .25 & .02 \\
\hline Benevolence & $.38^{* *}$ & .04 & .16 & .09 \\
\hline Universalism & .19 & .11 & .16 & $.62^{* *}$ \\
\hline \multicolumn{5}{|l|}{ Control group } \\
\hline Self-direction & .21 & $.28^{*}$ & -.16 & .20 \\
\hline Stimulation & $.32^{*}$ & $.60^{* *}$ & .08 & .20 \\
\hline Hedonism & .07 & $.70^{* *}$ & -.13 & -.13 \\
\hline Achievement & $.43^{* *}$ & $.42^{* *}$ & .06 & .15 \\
\hline Power & .18 & $.27^{*}$ & .10 & -.08 \\
\hline Security & $.45^{* *}$ & -.02 & $.50^{* *}$ & .25 \\
\hline Conformity & $.40^{* *}$ & -.07 & $.38^{* *}$ & .21 \\
\hline Tradition & $.40^{* *}$ & -.05 & $.52^{* *}$ & $.37^{* *}$ \\
\hline Benevolence & $.47^{* *}$ & $.29^{*}$ & $.28^{*}$ & $.44^{* *}$ \\
\hline Universalism & $.38^{* *}$ & $.26^{*}$ & $.27^{*}$ & $.53^{* *}$ \\
\hline
\end{tabular}

Note. ${ }^{*} p<.050,{ }^{*} p<.010$.

nature relationships are presented in terms of ambiguity between fear and development. On the one hand, mysterious and unbridled nature elicits fear and arouses existential anxieties, while on the other hand, survival in a dynamic and changing environment requires openness to experience and development of cognitive and behavioral skills.

The presented results allow one to some extent to go beyond the opposition of the spiritual and material world in dealing with the knowledge of the inevitability of death. If religion as well as pursuit of material goods failed to give objective meaning to existence, all one can do is to experience what life has to offer (stimulation, self-direction) and being aware of one's interdependence with others and nature (universalism, natural mode of symbolic immortality). The results obtained in the present study seem to confirm this kind of strategy among non-religious adolescents (see also: Landau, Greenberg, \& Kosloff, 2010).

\section{REFERENCES}

Cieciuch, J. (2013). Ksztattowanie się struktury i hierarchii wartości od dzieciństwa do wczesnej dorosłości [Development of value structure and hierarchy from childhood to early adulthood]. Warszawa: Liberi Libri.

CBOS (2009, March). Wiara i religijność Polaków dwadzieścia lat po rozpoczęciu przemian. Komunikat $z$ badań [Faith and religiosity of Poles after twenty years of transformation. Survey report]. Retrieved from: http://www.cbos.pl/SPISKOM.POL/ 2009/K_034_09.PDF

Dechesne, M., Pyszczynski, T., Arndt, J., Ransom, S., Sheldon, K. M., van Knippenberg, A., \& Janssen, J. (2003). Literal and symbolic immortality: The effect of evidence of literal immortality on self-esteem striving in response to mortality salience. Journal of Personality and Social Psychology, 84, 722-737. DOI: 10.1037/0022-3514.84.4.722 
de St. Aubin, E. (1996). Personal ideology polarity: Its emotional foundation and its manifestation in individual value systems, religiosity, political orientation, and assumptions concerning human nature. Journal of Personality and Social Psychology, 71, 152-165. DOI: 10.1037/0022-3514.71.1.152

Florian, V., \& Mikulincer, M. (1998). Symbolic immortality and the management of the terror of death. The moderating role of attachment style. Journal of Personality and Social Psychology, 74, 725-734.

Greenberg, J., Simon, L., \& Pyszczynski, T. (1992). Terror management and tolerance: Does mortality salience always intensify negative reactions of others who threaten one's worldview? Journal of Personality and Social Psychology, 63, 212-220.

Heine, S. J., Proulx, T., \& Vohs, K. D. (2006). The Meaning Maintenance Model: On the coherence of social motivation. Personality and Social Psychology Review, 10, 88-110.

Koole, S. E., \& van den Berg, A. E. (2004). Paradise lost and reclaimed: a motivational analysis of human-nature relations. In: J. Greenberg, S. Koole, \& T. Pyszczynski (eds.), Handbook of Experimental Existential Psychology (pp. 86-103). New York: Guilford Press.

Landau, M., Johns, M., Greenberg, J., Pyszczynski, T., Martens, A., Goldenberg, J., \& Solomon, S. (2004). A Function of Form: Terror Management and Stucturing the Social World. Journal of Personality and Social Psychology, 87, 190-210.

Landau, M., Greenberg, J., \& Kosloff, S. (2010). Coping with life's one uncertainty: a terror management perspective on the existentially uncertain self. In: R. Arkin, K. Oleson, \& P. Carroll (eds.), Handbook of the uncertain self. New York: Psychology Press.

Landau, M. J., Greenberg, J., Solomon, S., Pyszczynski, T., \& Martens, A. (2006). Windows into nothingness: Terror management, meaninglessness, and negative reactions to modern art. Journal of Personality and Social Psychology, 90, 879-892.

Lifton, R. J. (1979). The broken connection. New York: Simon \& Schuste.

Matthews, R. C., \& Kling, K. (1988). Self transcendence, time perspective and prosocial behavior. Journal of Voluntary Action Research, 17, 4-24.

Saroglou, V., Delpierre, V., \& Dernelle, R. (2004). Values and religiosity: A meta-analysis of studies using Schwartz's model. Personality and Individual Differences, 37, 721-734. DOI: 10.1016/j. paid.2003.10.005

Schwartz, S. H. (1992). Universals in the content and structure of values: Theoretical Advances and empirical tests in 20 countries. In: M. Zanna (ed.), Advances in experimental social psychology (Vol. 25, pp. 1-65). London: Academic Press.

Schwartz, S. H., Melech, G., Lehmann, A., Burgess, S., Harris, M., \& Owens, V. (2001). Extending the cross-cultural validity of the theory of basic hu- man values with a different method of measurement. Journal of Cross-Cultural Psychology, 32, 519-542.

Solomon, S., Greenberg, J., \& Pyszczynski, T. (2000). Pride and prejudice. Fear of death and social behavior. Current Directions in Psychological Science, 9, 200-204. 